\title{
Contraceptive use and method preference among HIV positive women in Addis Ababa, Ethiopia: a cross sectional survey
}

\author{
Hussen Mekonnen Asfaw* and Fikre Enquselassie Gashe
}

\begin{abstract}
Background: Prevention of unplanned pregnancies among people living with HIV is essential component of "Global Plan" even in the context of expanded access to highly active antiretroviral therapy (HAART). The study aimed to assess whether contraceptive use and method preference varied by the use of HAART among HIV positive women in Addis Ababa, Ethiopia.

Methods: A cross sectional facility based survey was conducted from June to October, 2012 information was gathered using interviewer administered questionnaire and document review was conducted to confirm HIV status and clinical review. A sample of 1418 HIV positive women including 770 women receiving HAART and 648 HAART-naïve recruited randomly from different health institutions in Addis Ababa. Data were principally analyzed using logistic regression.

Result: Overall, 71\% women reported using contraception (75\% among HAART users and 65\% HAART naïve women). Male condom and injectables are the most preferred contraceptive methods among both groups. The odds of contraceptive use among HAART users was higher (AOR 1.60,95\% Cl; 1.30-2.12) than HAART naïve women. In addition to this, presence of partner (AOR $2.32,95 \% \mathrm{Cl} 1.60-3.40$ ), disclosure of HIV status to husband (AOR 2.23; 95\% Cl 1.21-4.12), presence of living children: one (AOR 1.7; 95\% Cl 1.03-2.40), two (AOR 2.6; $95 \% \mathrm{Cl} 1.7-4.02$ ) and three (AOR 3.3; $95 \% \mathrm{Cl}$ 1.90-5.60) respectively were found to be predictors of contraceptive use among HIV positive women.

Conclusion: The contraceptive profile of women in the study area mainly dependent on male condom use, this indicates the need to better integrate tailored counseling and contraceptive options with care and support activities that targets HIV positive women. Moreover, emphasis should be given to dual contraceptive method use along with their regular follow up irrespective of their HAART use.
\end{abstract}

Keywords: Contraceptive use, HIV positive women, HAART use, Addis Ababa, Ethiopia

\section{Background}

Sub-Saharan Africa is the region most severely affected by HIV [1]. Women of productive age account for $58 \%$ of the people living with HIV [2] and 53\% of all adult deaths [3]. In Ethiopia, more women (2.9\%) than men (1.9\%) are living with HIV [4]. Most of these women are particularly vulnerable to HIV due to complex burden they have [5] including physiological, social vulnerability and gender inequalities [3].

\footnotetext{
* Correspondence: hussen_mk@yahoo.com

Department of preventive medicine, School of Public Health, Addis Ababa University, Addis Ababa, Ethiopia
}

Furthermore, HIV positive women have risk of unplanned pregnancies [6]. Worldwide, two in every five pregnancies are unplanned [7]. Previous studies of 42 subSaharan Africa countries, 10-65\% of women reported that their last pregnancy had been unplanned [8]. Similarly, $62 \%$ of women on ART from South African [9] and 59\% of HIV positive women from Kenya reported unplanned pregnancy [10].

Prevention of unintended pregnancy among HIV positive women is the second element of prevention of mother to child transmission of HIV (PMTCT) [11] which is an important means to address the associated problems of 
HIV positive women and children [12]. It is reported to be cost effective [13], improves quality of life [14], reduces maternal and child mortality [3,12,15-17] and reduces number of positive infants by keeping their mother alive [18].

Significant improvements have been demonstrated by PMTCT in low and middle income countries [19]. The percentage of pregnant women with HIV receiving antiretroviral therapy(ART) using PMTCT in sub Saharan Africa increased to $50 \%$ [3]. However, PMTCT efforts to date gave less emphasis to the contraceptives options [20].

Despite the potential contribution of family planning(FP) to the prevention of HIV infection [12] and unintended pregnancies [3], contraceptive use in sub-Saharan Africa remains low [21]. The percentage of married women aged 15-49 using modern contraceptive methods ranges from $12 \%$ in Mozambique and $14 \%$ in Ethiopia to $27 \%$ in Rwanda [4]. In addition, previous reports indicated that twenty five percent of women with HIV worldwide and one in four married women from sub-Saharan Africa has unmet need for family planning [22].

Even in the context of expanded access to ART for HIV-infected pregnant women, family planning still needs to be strengthened to avoid unintended pregnancies [23]. Existing evidence revealed that women living with HIV including those taking ARVs can use almost all contraceptive methods safely and effectively $[15,16]$ with variation in method preference [5,12,24-27].

Previous studies from different parts of Ethiopia reported that of those who have ever used at least one contraceptive method after HIV diagnosis, condom, injectables and abstinence were reported to be the most preferred methods [28-30]. However, information on informed choice of contraceptive methods, reasons for selection of methods and the influence of HAART on the contraceptive use of women entering HIV care is scarce.

Ethiopia is the second populous country in Africa [31], characterized by high fertility of $5.4 \%$ children per woman [4], having more children is highly valued [32]. Moreover, majority of women deliver at home (usually without skilled attendant) where complications of childbirth cannot be addressed, including the risk of mother-tochild transmission of HIV [31]; identification of factors associated with contraceptive use and method preference among HAART using women is an important issue to be addressed.

Thus, given the importance of contraceptive use in preventing unintended pregnancy, perinatal transmission of HIV [3] and ART scale up in Ethiopia; it is worth to assess contraceptive use and method preference of HIV positive women. It is anticipated that this research will update existing knowledge, inform policy makers and programmers to support safer and healthier reproductive options among HIV positive women in the study area.

\section{Methods}

The study was conducted in health facilities of Addis Ababa, Ethiopia. In the country, Antiretroviral treatment began in 2003 and free ART was launched in 2005 [33]. Since then, a total of five public hospitals and twenty five health centers have been offering ART [34]. About 124,983 people living with HIV were enrolled of whom 76,035 have started and 54,667 are currently on ART in the city [4]. Amhara is the predominant ethnic group and Amharic is commonly spoken language in the study area [35].

\section{Study design and sampling procedures}

A cross sectional survey was carried out at selected public health facilities (hospitals \& health center) of Addis Ababa between June and October, 2012. Non-pregnant women aged 18-49 years, reported having sexual relationship six months prior to the data collection period were eligible to participate in this study.

Sample size was computed using two-proportion formula with the assumption of proportion of contraceptive use among HIV positive women receiving HAART and HAART naïve being $86 \%$ and $82 \%$, respectively [12], with a minimum detectable odds ratio of 2 at $5 \%$ level of significance power of $90 \%$ with a design effect of 2 and $5 \%$ addition for non-response rate a total sample size of 1924. However, the number of women who satisfy the eligibility criteria at the records of the health facilities was 1418 (770 HAART users and 648 HAART- naïve).

Study participants were selected using multi-stage sampling technique. Initially, five hospitals and seven health centers were selected by lottery methods, and then the total sample size was proportionally allocated to the selected facilities according to the client load in each institution. Finally individual study subjects were selected using a systematic random sampling technique from the records of each selected facility.

\section{Data collection}

Data were collected using interviewer administered structured questionnaires adopted from previous similar study [12]. The questionnaire has been translated in to the local language (Amharic) by experts in both languages and back translated to English by another person to ensure consistency and accuracy. Data collectors were all female nurses recruited based on their previous experience in data collection, those who had previous training on ART and/or HIV counseling and fluency of the local language. Moreover, training was given for five consecutive days on interview techniques, sampling and ethical issues, emphasizing the importance of safety of participants and interviewers, minimization of under reporting and maintaining confidentiality. A pre-test of the questionnaire was conducted in selected ART units which were not included in 
the main study. The data collection process was closely supervised by the principal investigator.

\section{Measurements}

The primary outcome variable was self-reported contraceptive use for the previous six months prior to the data collection period. In this study contraceptive use was defined the use of any method including injectables (Depot), implants (implanol or jadelle), oral contraceptive pill (OCP), intra uterine contraceptive device (IUCD), male/female condom, diaphragm, permanent methods such as tubal ligation and hysterectomy. Dual contraceptive method was defined as use of primarily the male condom with hormonal or other contraceptive methods like IUCD. Consistent condom use was defined as the use of condoms always or frequently in all vaginal sexual relationships with casual and/or steady partners. Women who used condoms sometimes or rarely were regarded as inconsistent condom users.

Independent variables in this study included were age, education, employment, monthly household income, sexual partnership status, HIV sero-status of partner/ husband, number of living children, HIV test of children, disclosure of HIV status to partner/husband and discussion with partner/husband or health workers about contraception. Medical record review was also conducted to confirm HAART history and obtain clinical data including World Health Organization stage of disease and CD4 cell count.

Antiretroviral therapy (ART) is treatment of people infected with human immunodeficiency virus (HIV) using anti-HIV drugs [36]. The standard treatment consists of a combination of at least three drugs (often called "highly active antiretroviral therapy" or HAART) that suppress HIV replication [37]. Highly active anti retroviral therapy (HAART) use defined as use of one of three antiretroviral medications either Efaveranze (EFV) or Neverapin (NVP) based [5,12,38] first line drugs or use of combination drugs with protease inhibitors(PIs) backbone of second line drugs [38]. We considered women to be HAART users if they had been receiving HAART for at least one month and HAART-naive if they had never taken HAART, prior to the data collection period.

\section{Analysis}

The pre coded responses were double entered in EPI Info version 3.5.2 software, for checking its consistency then was exported to SPSS for window version 20 for statistical analysis. Uses, preference and reasons for selection of contraceptive methods are presented using descriptive statistics. Variables found to be significant at bivariate level, $(\mathrm{P}<0.05)$, were selected and included in to multiple logistic regression models. Then multiple logistic regression analyses were used to calculate Odds ratio with 95\% confidence interval to estimate association and to control the potential confounding variables. Strength and direction of the association between contraceptive use and potential socio-demographic, reproductive health and clinical factors were presented using odds ratios relative to the reference category and 95\% confidence levels.

\section{Ethical considerations}

The research was approved for scientific and ethical integrity by the Institutional Review Board (IRB) of College of Health Sciences, Addis Ababa University. Written permission was obtained from health bureau of the Addis Ababa city government. Consent was obtained from medical directors and respective unit heads at each health institutions. Verbal consent was also obtained from individual clients. In order to make informed decision sufficient information was given to each participant. Confidentiality was strictly maintained for each piece of information and the interview was conducted in strict private place. At the end of the interview general information, referral and follow up linkages were made for those who need.

\section{Results}

Socio-demographic characteristics of study participants

Of the total 1418 women who participated in this study, $423(29.8 \%)$ were in the age range of $30-34$ years, with mean (standard deviation) of $31.1( \pm 5.5)$. The study participants were predominantly Orthodox Christians 1109 (78.2\%) and Amhara 849(59.9\%) by religion and ethnicity, respectively. Occupationally, 373 (26.3\%) participants had their own private business and 292(20.6\%) were housewives. Concerning educational status of the participants, $538(37.9 \%)$ have completed grade $1-8,466(32.9)$ grade 9-12 and 133(9.4\%) with higher education. Four hundred nineteen (29.5) earn monthly income of less than 1000 Ethiopian birr and 390 (27.5\%) women were with no monthly income. Concerning marital status, about $62 \%$ of the participants are currently married/cohabited and 242 (17.1\%) were single (Table 1 ).

\section{Reproductive and clinical characteristics of study participants}

About 55\%(422/769) of HAART users and 45\% (347/769) HAART naïve women had recent CD4 counts of 350 cell/ $\mathrm{mm} 3$ and $42 \%(363 / 863)$ and 58\% (500/863) HAART users and HAART naïve, respectively were in WHO stage of disease I or II. About 70.3\% (997/1418) of the study participants reported ever had sexual partner in their life time. Of these women who had partners, $81.8 \%$ (816/997) reported that their partners were tested for HIV, and $73.8 \%$ $(602 / 816)$ are positive for HIV. Of the total study participants, 463(32.7\%) women reported having one child, 321 (22.6\%) two children and 428(30.2\%) no children. About 59\% (507/859) and 41\% (352/859) HAART users and HAART naïve women, respectively, had disclosed HIV 
Table 1 Socio-demographic characteristics of HIV positive women in Addis Ababa, Ethiopia $(n=1418)$

\begin{tabular}{|c|c|c|c|}
\hline \multirow[t]{2}{*}{ Socio-demographic characteristics } & HAART users $(n=770)$ & HAART Naïve $(n=648)$ & Total \\
\hline & No (\%) & No (\%) & No (\%) \\
\hline \multicolumn{4}{|l|}{ Age (in years) } \\
\hline $18-24$ & $58(7.5)$ & $91(14.0)$ & $149(10.5)$ \\
\hline $25-29$ & $219(28.4)$ & $203(31.3)$ & $422(29.8)$ \\
\hline 30-34 & $245(31.8)$ & $178(27.5)$ & $423(29.8)$ \\
\hline 35-39 & $186(24.2)$ & $122(18.8)$ & $308(21.7)$ \\
\hline $40-49$ & $62(8.1)$ & $54(8.3)$ & $116(8.2)$ \\
\hline Mean (SD) Age in years & $31.6( \pm 5.2)$ & $30.4( \pm 5.8)$ & $31.1( \pm 5.5)$ \\
\hline \multicolumn{4}{|l|}{ Ethnicity } \\
\hline Amhara & $462(60.0)$ & $387(59.7)$ & $849(59.9)$ \\
\hline Oromo & $167(21.7)$ & $147(22.7)$ & $314(22.1)$ \\
\hline Gurage & $70(9.1)$ & $54(8.3)$ & $124(8.7)$ \\
\hline Tigrea & $47(6.1)$ & $32(4.9)$ & $79(5.6)$ \\
\hline Others (Silte,gamo, welayta, yem, Sidama) & $24(3.1)$ & $28(4.3)$ & $52(3.7)$ \\
\hline \multicolumn{4}{|l|}{ Religion } \\
\hline Orthodox Christian & $604(78.4)$ & $505(78.0)$ & $1109(78.2)$ \\
\hline Muslim & $84(10.9)$ & $76(11.7)$ & $160(11.3)$ \\
\hline Others (Protestant, catholic, Jubbah) & $82(10.6)$ & $67(10.3)$ & $149(10.5)$ \\
\hline \multicolumn{4}{|l|}{ Marital status } \\
\hline Single & $126(16.4)$ & $116(17.9)$ & $242(17.1)$ \\
\hline Married/cohabited & $488(63.4)$ & $397(61.3)$ & $885(62.4)$ \\
\hline Widowed & $81(10.5)$ & $55(8.5)$ & $136(9.6)$ \\
\hline Divorced & $75(9.7)$ & $80(12.3)$ & $155(10.9)$ \\
\hline \multicolumn{4}{|l|}{ Educational status } \\
\hline illiterate & $91(11.8)$ & $78(12.0)$ & $169(11.9)$ \\
\hline Informal education & $50(6.5)$ & $62(9.6)$ & $112(7.9)$ \\
\hline Grade 1-8 completed & $273(35.5)$ & $265(40.9)$ & $538(37.9)$ \\
\hline Grade 9-12 completed & $290(37.6)$ & $176(27.2)$ & $466(32.9)$ \\
\hline above 12 grade & $66(8.6)$ & $67(10.3)$ & $133(9.4)$ \\
\hline \multicolumn{4}{|l|}{ Occupation } \\
\hline unemployed & $131(17.0)$ & $133(20.5)$ & $264(18.6)$ \\
\hline Housewife & $166(21.6)$ & $126(19.4)$ & $292(20.6)$ \\
\hline Daily laborer & $96(12.5)$ & $112(17.3)$ & $208(14.7)$ \\
\hline Merchant & $40(5.2)$ & $36(5.6)$ & $76(5.4)$ \\
\hline CSW & $18(2.3)$ & $13(2.0)$ & $31(2.2)$ \\
\hline Government worker & $90(11.7)$ & $84(30.6)$ & $174(12.3)$ \\
\hline Private business & $229(29.7)$ & $144(22.2)$ & $373(26.3)$ \\
\hline \multicolumn{4}{|l|}{ Monthly Income (in Birr)* } \\
\hline No Income & $192(24.9)$ & 198 (30.6) & $390(27.5)$ \\
\hline Birr below 500 & $217(28.2)$ & $144(22.2)$ & $361(25.5)$ \\
\hline Birr 500-1000 & $227(29.5)$ & $192(29.6)$ & $419(29.5)$ \\
\hline Birr 1001-3000 & $112(14.5)$ & $97(15.0)$ & $209(14.7)$ \\
\hline Birr above 300 & $22(2.9)$ & $17(2.6)$ & $39(2.8)$ \\
\hline
\end{tabular}

*Birr $=(1 \mathrm{USD}=18.80 \mathrm{ETB})$. 
status to partner/husband. Furthermore, 66.6\%(664/997) women reported they had open discussion with partner/ husband (Table 2).

\section{Use and preference of contraceptive methods}

Overall contraceptive use was 71\% (75\% (579/770) and 65\% (422/648) among HAART users and 42\% HAARTnaïve women, respectively). Four hundred five (28.8\%) reported did not use contraceptive methods six months prior to the data collection period while contraceptive status was not known for 9 (0.6\%) women (Table 3$)$. In general male condom is the most preferred contraceptive method $45.7 \%$ (468/1001) followed by injectables 30.5\% (306/1001) (Table 3).

\section{Reasons given in choosing contraceptive methods}

The primary reason given for contraceptive use was for protection against STIs in 28\% (281/1001) followed by prevention of unwanted pregnancy in 21\% (208/1001), among women using any method. Other reasons mentioned were convenient to use $18 \%$ (180/1001), easy to use $14 \%(138 / 1001)$, does not interfere with sexual activity $8 \%(82 / 1001)$, advise of health workers 5\% (50/1001), and the like (Figure 1).

\section{Factors associated with contraceptive use}

Using the logistic regression model, a number of sociodemographic, HAART use, sexual history, disclosure behavior and clinical factors were identified as significant predictors of the association of contraceptive use (Table 4).

The results showed that HAART use has influence on women's decision to use contraceptives compared to HAART naïve women, the odds of contraceptive use among HAART users was significantly higher, adjusted for other potential confounders (AOR 1.60, 95\% CI; 1.30 to 2.12). Similarly, women who had sexual partners currently were more likely to use contraceptives than women with no partners (AOR 2.32, 95\% CI 1.60 to 3.40). On the other hand, married/cohabited (AOR 0.41, 95\% CI 0.21 to 0.80 ) and widowed women (AOR $0.31,95 \%$ CI 0.12 to 0.84) respectively, had less likely to use contraceptive methods compared to that of single women.

Disclosure of HIV status, especially, with sexual partner has significant association with contraceptive use, women who disclosed their HIV status to partner were about two times more likely to use contraceptive than women who did not (AOR 2.23, 95\% CI 1.21 to 4.12). Furthermore, women who reported open discussion with their partner/husband were about two times more likely to use contraceptives than those who reported no discussion (AOR 2.0, 95\% CI; 1.60 to 2.60).

Contraceptive use also increased by the number of living children women have. The odds of contraceptive use for women who have one child (AOR 1.7, 95\% CI 1.03 to 2.40), two children (AOR 2.6; 95\% CI 1.7 to 4.02) and three or more children (AOR 3.3, 95\% CI 1.90 to 5.60 ), respectively, were higher than women with no children. Similarly, the odds of contraceptive use was higher for women whose children are tested for HIV than women who did not (AOR, 1.6; 95\% CI; 1.01 to 2.40).

\section{Discussion}

The issue of contraceptive use and method preference among women enrolled in HIV care and treatment programs in the study area has important implications for the health of women and their infants. Overall the proportion of contraceptive use was $71 \%$ irrespective of their HAART use. Previous studies from Uganda and South Africa reported higher than our finding $85 \%$ and $78 \%$, respectively $[5,12]$. On the other hand, our finding showed higher proportion than previous findings from other developing countries, which reported between 28 and 53\% [39-42] and than earlier reports within the country reported 43 to $54 \%[29,30,43]$. The difference is associated with study time and study subject differences.

The result is different from contraceptive use of the general female population in Addis Ababa reported 63\% [44]. The most probable reason might be that HIV positive women have frequent contact with health care providers and demand for contraceptives might be higher than the general population.

In the logistic model, we found that, adjusted for potential confounders, contraceptive use was significantly higher among women receiving HAART than HAART naïve; which was also reported by previous studies from Uganda and South Africa $[5,12]$. This may be a reflection of the fact that continual exposures to secondary prevention messages along with ART might have impact on contraceptive use. Even though, male condom is the most preferred method by all study participants, it was higher among those receiving HAART compared to HAART naïve women (54 vs $37 \%$, respectively).

While the use of dual contraceptive methods (condom with other methods) is safe to prevent unintended pregnancy and HIV [25,45]. However, low proportion (14.7\%) of dual contraceptive method use was observed among HAART users. This may reflect that the study population is at risk of acquiring sexually transmitted infection including drug resistant HIV virus.

Our findings has also showed that women with living children have reported contraceptive use than those with no children; the result was consistent with studies reported from Uganda and South Africa [5,12]. This suggests that the desire to have children among those with no children is higher for obvious reasons and consequently avoiding contraceptive use.

Furthermore, women who have open discussion with partner or health care providers have better contraceptive 
Table 2 Reproductive and clinical characteristics of HIV positive women in Addis Ababa, Ethiopia $(n=1418)$ Reproductive and clinical history

HAART use
No (\%)
$466(79.2)$
$225(45.9)$
$79(21.6)$

$350+$ cells $/ \mathrm{mm}^{3}$

\section{Current CD4 count}

0-199 cells $/ \mathrm{mm}^{3}$

200-349 cells $/ \mathrm{mm}^{3}$

$350+$ cells $/ \mathrm{mm}^{3}$

WHO stage of Disease

Stage I/II

Stage III/IV

Presence of partner

Yes

No

Partner tested $(n=997)$

Yes

No

I do not know

Test result of current partner $(n=816)$

Positive

Negative

I do not know

Child tested $(n=990)$

Yes

No

\section{Disclose HIV status to anybody}

Yes

No

Disclosed HIV status to husband $(n=997)$

Yes

No

Number of living children

0

1

2

$3+$

Discussed with husband/Partner $(n=997)$

Yes

No

Discussed with HCWs*

Yes

No

*HCWs: health care workers.

125 (64.4)

$223(49)$

$422(55)$

363 (42)

$407(73.3)$

$560(56.2)$

$210(50)$

479 (59)

47 (48)

$34(40)$

347 (58)

119 (60)

13 (87)

175 (51)

$722(56.3)$

48 (34.7)

507 (59)

$218(51)$

$260(51)$

$180(56)$

$112(54.3)$

$384(57.8)$

$176(52.8)$

553 (54.7)

$217(52.8)$
HAART naïves $(n=648)$

No (\%)

Total

No (\%)

97 (20.8)

563 (39.7)

$265(54.1)$

$490(34.6)$

365 (25.7)

69 (35.6)

194 (13.7)

232 (51)

455 (32.1)

347 (45)

769 (54.2)

500 (58)

863 (60.9)

148 (26.7)

555 (39.1)

437 (43.8)

997 (70.3)

$211(50)$

421 (29.7)

337 (41)

816 (81.8)

50 (52)

97 (9.7)

50 (60)

84 (8.4)

255 (42)

602 (73.8)

73 (40)

2 (13)

199 (24.4)

273 (42)

165 (40)

650 (65.6)

558 (43.7)

90 (65.3)

$1280(90.3)$

352 (41)

859 (86.2)

85 (61.6)

138 (13.8)

$210(40)$

428 (30.2)

203 (49)

463 (32.7)

141 (44)

321 (22.6)

94 (45.7)

206 (14.5)

$280(42.2)$

664 (66.6)

$157(47.2)$

333 (33.4)

457 (45.3)

$1010(71.2)$

$191(47.2)$

408 (28.8) 
Table 3 Use and preference of contraceptive methods among HIV positive women in Addis Ababa, Ethiopia

\begin{tabular}{|c|c|c|c|}
\hline Type of contraceptives & $\begin{array}{l}\text { HAART users }(n=770) \\
\text { No }(\%)\end{array}$ & $\begin{array}{l}\text { HAART Naives }(n=648) \\
\text { No }(\%)\end{array}$ & $\begin{array}{l}\text { Total } \\
\text { No }(\%)\end{array}$ \\
\hline \multicolumn{4}{|l|}{ Contraceptive use } \\
\hline Yes & $579(75.2)$ & $422(65.1)$ & 1001 (70.6) \\
\hline No & $186(24.2)$ & $222(54.3)$ & $408(28.8)$ \\
\hline Not known & $5(0.6)$ & $4(0.6)$ & $9(0.6)$ \\
\hline \multicolumn{4}{|l|}{ Method preference } \\
\hline Injectables (Depot) & $146(25.2)$ & $160(37.9)$ & $306(30.5)$ \\
\hline Oral contraceptive pills (OCP) of available type & $55(9.4)$ & $46(11)$ & $101(10.0)$ \\
\hline Intra uterine contraceptive device (IUCD) & $16(2.7)$ & $12(2.8)$ & $28(2.8)$ \\
\hline Implant (Jaddelle or Implanon) & $48(8.2)$ & $45(10.5)$ & $93(9.2)$ \\
\hline Consistent male condom use & $310(53.5)$ & $158(37.4)$ & $468(46.7)$ \\
\hline Female condom & $4(0.7)$ & $1(0.2)$ & $5(0.5)$ \\
\hline \multicolumn{4}{|l|}{ Categories of contraceptives methods } \\
\hline Dual contraceptive methods (condom and hormonal methods) & $98(14.7)$ & $114(21.6)$ & $212(18)$ \\
\hline Barrier Methods (male or female condom) & $317(47.5)$ & $161(30.6)$ & $478(40)$ \\
\hline Hormonal methods (OCPs, Implant and Depot) & $249(37.5)$ & $251(39.9)$ & $500(42)$ \\
\hline
\end{tabular}

N.B. a woman may have reported the use of $\geq 1$ method value will not be added to $100 \%$.

profile than their counterparts. This suggests that disclosure of HIV status to a partner may be important to get support from family and discussion can clarify uncertainties about contraceptives and possibly to strengthen confidence of women. Besides women who knew the HIV status of their children reported contraceptive use than their counter parts, this could be related to women who tested their children have better exposure and more concerned on the prevention of unintended pregnancies.

Our study has several limitations; due to crosssectional nature we are unable to make definitive conclusions on cause and effect relation. The association could only be discussed in terms of plausibility. Furthermore, social desirability and stigma may have biased respondents' answers and may not be generalizable to HIV-positive female population in the care.

As to the strengths of this study, the respondents have been selected by random sampling technique with relatively large sample size. Again, the team already adopted instrument conducted in other developing countries [12]. Precautions have been taken in selection of experienced data collectors.

\section{Conclusion}

The study identified that HIV positive women in general and women receiving HAART in particular are more likely to use contraceptives with preference of male condom. Its protection against STIs followed by prevention of

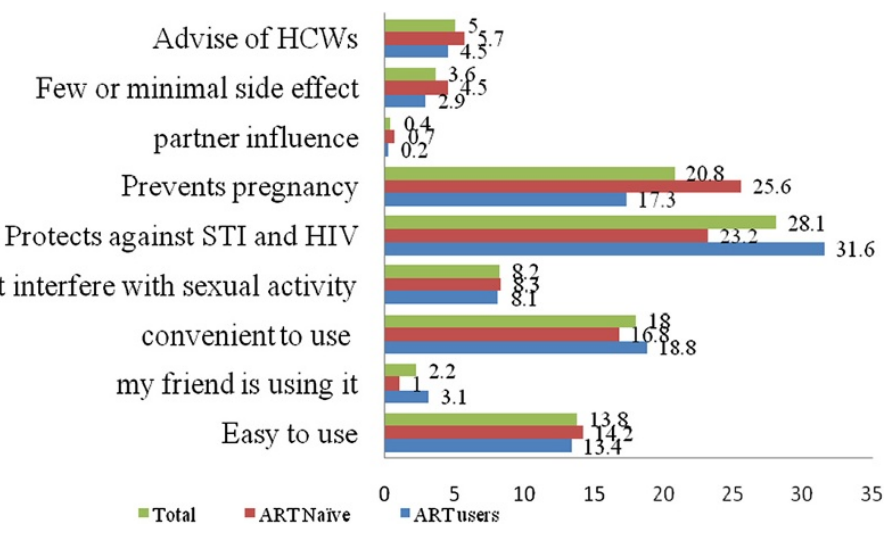

Figure 1 Reasons given in choosing methods of prevention among HIV positive women in Addis Ababa, Ethiopia. 
Table 4 Adjusted analyses of variables associated with contraceptive use among women in Addis Ababa, Ethiopia

\begin{tabular}{|c|c|c|c|}
\hline \multirow[t]{3}{*}{ Variables } & \multicolumn{2}{|c|}{ Contraceptive use } & \multirow{3}{*}{$\begin{array}{l}\text { Adjusted odds ratio } \\
\text { AOR }(95 \% \mathrm{Cl})\end{array}$} \\
\hline & Yes & No & \\
\hline & No. (\%) & No. (\%) & \\
\hline \multicolumn{4}{|l|}{ HAART use } \\
\hline No & $422(42.2)$ & $226(55.4)$ & 1.00 \\
\hline Yes & $579(57.8)$ & $191(45.6)$ & $1.6(1.30-2.12)^{* *}$ \\
\hline \multicolumn{4}{|c|}{ Presence of partner } \\
\hline No & $236(26.6)$ & $185(44.4)$ & 1.00 \\
\hline Yes & $765(76.4))$ & $232(55.6)$ & $2.32(1.60-3.40)^{* *}$ \\
\hline \multicolumn{4}{|c|}{ Disclosed HIV status to husband } \\
\hline No & $87(11.4)$ & $51(22.1)$ & 1.00 \\
\hline Yes & $679(88.6)$ & $180(77.9)$ & $2.23(1.21-4.12)^{* *}$ \\
\hline \multicolumn{4}{|c|}{ Discussed with husband } \\
\hline No & $240(31.3)$ & $99(42.9)$ & 1.00 \\
\hline Yes & $526(68.7)$ & $132(57.1)$ & $2.0(1.60-2.60)^{* *}$ \\
\hline \multicolumn{4}{|c|}{ Discussed with HWs } \\
\hline No & $242(24.9)$ & $166(39.8)$ & 1.00 \\
\hline Yes & $759(75.1)$ & $251(60.2)$ & $1.60(1.20-2.03)^{* *}$ \\
\hline \multicolumn{4}{|c|}{ Number of living Children } \\
\hline 0 & $275(27.5)$ & $153(36.7)$ & 1.00 \\
\hline 1 & $329(32.9)$ & $134(32.1)$ & $1.7(1.03-2.40)^{* *}$ \\
\hline 2 & $241(24.1)$ & $80(19.2)$ & $2.6(1.7-4.02)^{* *}$ \\
\hline $3+$ & $156(15.6)$ & $50(12.0)$ & $3.3(1.90-5.60)^{* *}$ \\
\hline \multicolumn{4}{|l|}{ Marital status } \\
\hline Single & $168(16.8)$ & $74(17.7)$ & 1.00 \\
\hline Married/cohabited & $673(67.2)$ & $212(50.8)$ & $0.41(0.21-0.80)^{*}$ \\
\hline Widowed & $73(7.3)$ & $63(15.1)$ & $0.31(0.12-0.84)^{*}$ \\
\hline Divorced & $87(8.7)$ & $68(16.3)$ & $0.80(0.30-2.30)$ \\
\hline \multicolumn{4}{|c|}{ Child tested for HIV } \\
\hline No & $236(32.5)$ & $104(39.3)$ & 1.00 \\
\hline Yes & $490(67.4)$ & $160(60.6)$ & $1.60(1.10-2.40)^{*}$ \\
\hline
\end{tabular}

*P value $<0.05$ **P-value $<0.001$.

Adjusted for age, education and other SES.

unwanted pregnancy and convenient to use were among the reasons mentioned for selection of the contraceptive methods. Furthermore, having one or more living children, disclosure of HIV status to sexual partner, open discussion with partner or health care workers found to be predictors of contraceptive use in the study area. Low proportion of dual contraceptive method use was observed among HAART users. This may reflect that the study population is at risk of acquiring sexually transmitted infection including drug resistant HIV virus.

The contraceptive profile of women in the study area mainly dependent on male condom use, this indicates the need to better integrate tailored counseling and contraceptive options with care and support activities that targets HIV positive women. Moreover, emphasis should be given to dual contraceptive method use along with their regular follow up irrespective of their HAART use.

Lastly extensive and longitudinal study is needed to validate current findings so as to inform for policy makers to establish better sexual and reproductive health services for positive women to have planed and safe fertility goal.

\section{Competing interests}

We declare that there are no financial or non-financial competing interests related to this study.

\section{Authors' contributions}

Both authors contributed equally during design and conduct of the study. $\mathrm{HM}$ and FE participated in data collection, statistical analysis and

interpretation of findings. HM prepared the draft then FE revised the draft of 
the paper. The two authors read and approved the final content of the manuscript.

\author{
Acknowledgements \\ We are very much grateful to Addis Ababa University for funding the study. \\ We would like to express our most sincere thanks to the women who \\ participated in this study, for sharing this personal and important \\ information with us; we also extend our thanks to all data collectors \\ participated throughout the process.
}

Received: 4 November 2013 Accepted: 2 June 2014 Published: 6 June 2014

\section{References}

1. UNAIDS WHO: Global HIV/AIDS Response-Epidemic update and health sector progress towards Universal Access-Progress Report. Geneva, Switzerland: UNAIDS; 2011

2. UNAIDS: Global Report, "UNAIDS report on Global AIDS Epidemic,". Geneva, Switzerland: UNAIDS; 2012.

3. UNAIDS: Report on HIV Epidemic in Eastern and Southern Africa. Geneva, Switzerland: Regional Report UNAIDS; 2013.

4. Federal Ministry of Health Ethiopia FMoHE: Health and Health Related Indicators. Addis Ababa, Ethiopia: FMOHE; 2011.

5. Andia I, Kaida A, Maier M, Guzman D, Emenyonu N, Pepper L, David R, Robert S: Highly active antiretroviral therapy and increased use of contraceptives among HIVpositive women during expanding access to antiretroviral therapy in Mbarara, Uganda. Am J Public Health 2009, 99(2):340-347.

6. Koenig LJ, Espinoza L, Hodge K, Ruffo N: Young, sero positive, and pregnant: epidemiologic and psychosocial perspectives on pregnant adolescents with human immunodeficiency virus infection. Am J Obstet Gynecol 2007, 197(3 Supple):S123-S131.

7. Zimbwa I, Vwalika B: Association Between Unplanned Pregnancy and HIV Seropositivity Disclosure to Marital/Cohabitating Partner Among Post-natal Women in Lusaka, Zambia. Med J Zambia 2010, 37(4):205-215.

8. Hubacher D, Mavranezouli I, McGinn E: Unintended pregnancy in sub-Saharan Africa: magnitude of the problem and potential role of contraceptive implants to alleviate it. Contraception 2008, 78:73-78.

9. Schwartz SR, Rees H, Mehta S, Venter WDF, Taha TE, Black V: High Incidence of Unplanned Pregnancy after Antiretroviral Therapy Initiation: Findings from a Prospective Cohort Study in South Africa. PLOS ONE 2012, 7(4):e36039.

10. Akelo V, Girde S, Borkowf CB, Angira F, Achola K, Lando R, Mills LA, Thomas TK, Shirley Lee L: Attitudes toward Family Planning among HIV-Positive Pregnant Women Enrolled in a Prevention of Mother-To-Child Transmission Study in Kisumu, Kenya. PLOS ONE 2013, 8(8):e66593. doi:10.1371/journal. pone.0066593.

11. Federal Ministry of Health Ethiopia FMoHE, Federal HIV/AIDS Prevention and Control Office FHAPCO: Guidelines for Prevention of Mother-to-Child Transmission of HIV in Ethiopia. Addis Ababa: FMoH; 2007:1-3.

12. Kaida A, Laher F, Strathdee SA, Money D, Janssen PA, Hogg R, Gray G: Contraceptive Use and Method Preference among Women in Soweto South Africa The Influence of Expanding Access to HIV Care and Treatment Services. PLOS ONE 2010, 5(11):e13868. doi:10.1371/journal. pone.0013868.

13. Raynols HW, Janowitiz B, Homan $R$, Johonson L: The value of contraception to Prevent Perinatal HIV Transmission. Sex Transm Dis 2006, 33(6):350-356.

14. World Health Organization WHO: Communicating Family Planning in Reproductive Health. Geneva, Switzerland: WHO. Available from: www.who.int/entity/reproductivehealth/publications/family_planning.

15. Baylies C: The impact of HIV on family size preference in Zambia. Reprod Health Matters 2000, 8:77-86.

16. USAID: Priorities for Family Planning and HIV/AIDS Integration, Maximizing Access and Quality (MAQ) Initiativ. Available from: www.maqweb.org.

17. Cleland J, Bernstein S, Ezeh A, Faundes A, Glasier A, Innis J: Family Planning the unfinished agenda. Lancet. 2006, 368:1810-27.

18. UNFPA: Preventing HIV and Unintended Pregnancies. Strategic Framework 2011-2015. Available from: www.unfpa.org/public/home/ publications/pid/10575.
19. 19.World Health Organization: PMTCT Strategic Vision 2010-2015. WHO Geneva, Switzerland: Preventing Mother-to-Child Transmission of HIV to Reach the UNGASS and Millennium Development Goals; 2010.

20. Petruney $\mathrm{T}$, Robinson $\mathrm{E}$, Reynolds $\mathrm{H}$, Wilcher R, Cates W: Contraception is the best kept secret for prevention of mother-to-child HIV transmission. Bulletin World Health Organ; 2008:86. B. doi:10.2471/BLT.08.051458 available: http:// www.ncbi.nlm.nih.gov/pmc/articles/PMC2647467/.

21. Ngom P, Wilcher R, Kuyoh M, Dube H, Martin S, Kimani J, Nutley T, Maggwa N: Family planning needs in the context of the HIV/AIDS epidemic. In Findings from a three-country assessment. Kenya, South Africa and Zimbabwe: XXV IUSSP International Conference Tours; France; 2005.

22. Stefiszyn K: Health and Reproductive rights, HIV and the protocol to the African Charter on the right of women in Africa. ESR Review 2011, 12(4):12-15.

23. World Health Organization: Use of antiretroviral drugs for treating pregnant women and preventing HIV infection in infants. Geneva, Switzerland: WHO; 2012. Available from: http://whqlibdoc.who.int/hq/2012/who_hiv_ 2012.8_eng.Pdf.

24. Iliyasu Z, Abubakar I, Kabir M, Babashani M, Shuaib F, Aliy MH: Correlates of Fertility Intentions among HIV/AIDS Patients in Northern Nigeria. Afr J Reprod Health 2009, 13(3):71-83.

25. Mitchell HS, Stephens E: Contraception choice for HIV positive women. Sex Transm Infect 2004, 80(3):163-77.

26. Heard I, Potard V, Costagliola D, Kazatchkine MD: Contraceptive use in HIV-positive women. J Acquir Immune Defic Syndr. 2004, 36:714-20.

27. Massad LS, Evans CT, Wilson TE, Golub ET, Sanchez-Keeland L, Minkoff H, Weber K Watts DH: Contraceptive use among U.S.women with HIV. J Women's Health 2007, 5:657-666.

28. Debeko K, Seme A: Sexual and reproductive health needs and preferences of people living with HIV/AIDS in Southern Nations Nationalities and Peoples Region. Addis Ababa University, Department of Community Health: Masters thesis; 2007. unpublished.

29. Worku D: Fertility intension and Demand for Family Planning among People on ART Follow up in North Wollo. Ethiopia: 21ST Annual Public Health Conference; 2010:12.

30. Tamene W, Fantahun M: Fertility desire and family-planning demand among HIV-positive women and men undergoing antiretroviral treatment in Addis Ababa, Ethiopia. Afr J AIDS Res 2007, 6(3):223-7.

31. Federal Ministry of Health Ethiopia FMoHE: National Comprehensive PMTCT/ MNCH Training Package, Facilitator's Guide. Addis Ababa, Ethiopia: FMoHE; 2013:11-25.

32. Getachew M, Alemseged F, Abera M, Deribew A: Factors affecting fertility decisions of married men and women living with HIV in South Wollo Zone. North east Ethiopia Ethiop J Health Dev 2010, 24(3):214-20

33. Federal Ministry of Health Ethiopia FMOH: Antiretroviral Therapy Guidelines for Adult Patients in Ethiopia. Addis Ababa,Ethiopia: FMOHE; 2008.

34. Federal Ministry of Health Ethiopia FMOHE, Federal HIV/AIDS Prevention and Control Office FHAPCO: Monthly ART Update as of end of Tir 2002 E.C. Addis Ababa,Ethiopia; 2010. Available from: http://www.hapco.gov.et/index. php/resource-center/art-monthly-updates.

35. Central Statistics Agency of Ethiopia CSA, ORC Macro USA: Census Result 2007. Addis Ababa, Ethiopia: CSA; 2007:11.

36. Barthlett JG, Gallant JE (Eds): Medical management of HIV Infection: Ordering Information. 2nd edition. Baltimore, USA: John Hopkins University School of Medicine, John Hopkins; 2007:24-25.

37. Federal Ministry of Health FMoHE, I-TECH-Ethiopia: Comprehensive ART Training Manual for Physicians, Pharmacists and Nurses. FMoHE 2007, 1(1):10-12.

38. Federal Ministry of Heaalth FMoHE: Guideline for Adult HIV/AIDS care and treatment in Ethiopia. 2nd edition. Addis Ababa: FMoHE; 2008:6-7.

39. Nóbreg AA, Oliveira FA, Galvão MT, Mota RS, Barbosa RM, Dourado I, Kendall C, Kerr-Pontes LR: Desire for a Child Among Women Living with HIV/AIDS in Northeast Brazil. AIDS Patient Care STDs 2007, 21(4):261-267.

40. Muyindike W, Fatch R, Steinfield R, Matthews LT, Musinguzi N, Emenyonu NI, Martin JN, Hahn JA: Contraceptive Use and Associated Factors among Women Enrolling into HIV Care in Southwestern Uganda. Infect Dis Obstet Gynecol 2012, 2012:1-9. http://dx.doi.org/10.1155/2012/340782.

41. Ezechi OC, Gbajabiamilla TA, Gab-Okafor CV, Oladele DA, Ezeobi PM, O.Ujah IA: Contraceptive Behavior, Practices and associated factors among Nigerian women Livingwith Human Immunodeficiency virus infection. J HIV\& Hum Reprod 2013, 1(1):30-35. 
42. Umoh AV, Abah GM, Ekanem US: A study of fertility intentions of women in Uyo, Nigeria. J Public Health Epidemiol 2012, 4(1):14-8.

43. Assefa B: Fertility desire and FP use in PLWH on pre-ART and ART care in public facilities of Addis Ababa City Administration. EPHA Sponsored Masters thesis 2009, 12(12):131-136.

44. Central Statistics Agency,CSA Ethiopia: Ethiopia Demographic and Health Survey Report. Addis Ababa, Ethiopia: CSA; 2011.

45. World Health Organization, UNFPA: Sexual and reproductive health of women living with HIV/AIDS. In Guidelines on care, treatment and support for women living with HIV/AIDS and their children in resource-constrained settings. 2006:30-35.

doi:10.1186/1471-2458-14-566

Cite this article as: Asfaw and Gashe: Contraceptive use and method preference among HIV positive women in Addis Ababa, Ethiopia: a cross sectional survey. BMC Public Health 2014 14:566.

\section{Submit your next manuscript to BioMed Central and take full advantage of:}

- Convenient online submission

- Thorough peer review

- No space constraints or color figure charges

- Immediate publication on acceptance

- Inclusion in PubMed, CAS, Scopus and Google Scholar

- Research which is freely available for redistribution 